\title{
UAV use for prescribed after-burn mapping in Itatiaia National Park
}

\author{
Isabela Braga Belchior ${ }^{1}$, Luis Marcelo Tavares de Carvalho ${ }^{l}$, Samantha Ramos Gomes ${ }^{l}$, \\ Tassia Borges Arantes ${ }^{1}$, Eveline Aparecida Pereira ${ }^{1}$, Marcelo Souza Motta ${ }^{2}$
}

\footnotetext{
${ }^{1}$ Universidade Federal de Lavras (UFLA), Lavras, Brasil

${ }^{2}$ Instituto Chico Mendes de Conservação da Biodiversidade (ICMBio), Parque Nacional do Itatiaia, Brasil

*e-mail: isabela_bbelchior@hotmail.com
}

\begin{abstract}
This research was conducted in the Campos de Altitude located in Itatiaia National Park (INP). The vegetation is composed of grass and shrub strata characteristic of this type of phytophysiognomy, with the presence of endemic species of the area. Historically, since it is an area with the highest concentration of major fires, as of 2017, the conservation unit performs management actions aimed at increasing the knowledge of the ecological role of fire in the Campos de Altitude. The aim of this study was to perform a detailed classification of the scar left in the soil after prescribed burning, evaluating the effectiveness of the burning. The images were obtained on March 31, 2017, after two days of the prescribed burn, using an RGB sensor coupled to an unmanned aerial vehicle (UAV). After processing and orthomosaic generation, an image of the entire area with $8 \mathrm{~cm}$ of spatial resolution was obtained. Orthomosaic classification was made by object-based analysis. The algorithm used for segmentation was edge-based segmentation, the defined parameters were scale and merge, with values of 60 and 80, respectively. The land cover classes used in the classification were: vegetation, burnt vegetation, rocky outcrops, and water. The classification algorithm used was the Support Vector Machine (SVM). Accuracy was assessed using a confusion matrix and Kappa index. The SVM algorithm was found to be effective in the classification of high-spatial-resolution images, with an overall accuracy of $94.5 \%$ and a Kappa index of 0.92 . For the burnt vegetation class, the user's and producer's accuracy was $87.9 \%$ and $94 \%$, respectively. The mapping indicated that the prescribed burning was effective, achieving its objectives (reduction of combustible material and fragmentation of it in the landscape, in an area susceptible to fire). It was also observed that because it is a fire characterized by low intensity, an area of arboreal vegetation and areas of swamps within the area were not affected by fire.
\end{abstract}

Keywords: prescribed burning, Support Vector Machine, classification, INP 